http://dx.doi.org/10.4314/ajtcam.v11i1.4

\title{
PREVALENCE OF FUNCTIONAL SUPPLEMENT USE AMONG KOREAN ADOLESCENTS
}

\author{
Yo-Chan Ahn', Chang-Gue Son ${ }^{2 *}$
}

\author{
${ }^{1}$ Dep. of Health Service Management, Daejeon Univ., Daejeon 300-716, South Korea \\ ${ }^{2}$ Dept. of Oriental Internal Medicine, Daejeon Oriental Hospital of Daejeon Univ., Daejeon 301-724, South Korea \\ *E-mail: ckson@dju.kr
}

Dear editor:

Functional supplements are intended not only to provide nutrients, but also to increase the physical and mental well-being of their consumer. Based on increasing demand to reduce health risks and improve health quality, the functional supplement market has expanded; it was estimated to be worth over US $\$ 80$ billion worldwide in 2008 (Vergari et al., 2010). Given the abundant use of supplements, doubts regarding their benefits and risks represent a public health concern (Pascal, 2009). It is therefore important to identify the national status of functional supplement usage.

In this study, we surveyed the current prevalence and types of functional supplements including herbal medicines among middle- and high-school students using questionnaires. A total of 4,709 students (2,458 males and 2,251 females, aged 13-19 years), including 2,254 middleschool (650 males and 1,604 females) and 2,455 high-school students (1,808 males and 647 females), from four schools in Daejeon, South Korea, were included as subjects. The comparisons of the frequency and choice of functional supplements were analysed using Chi-square test with SPSS (SPSSs 18.0K for Windows; SPSS, Inc., Chicago, IL, USA).

As shown in table $1,35.8 \%$ of the students consumed at least one type of functional supplement or herbal products. The average prevalence of functional supplement use was higher among high-school students (40.7\% total, $40.6 \%$ males and $40.8 \%$ females) than middleschool students (30.5\% total, $29.5 \%$ males and $30.9 \%$ females). The statistical analysis showed significant difference between male and female students $(\mathrm{p}<0.01)$ as well as middle- and high-school students $(\mathrm{p}<0.01)$. We also surveyed the type of functional supplements which the students were consuming. The students consumed primarily multivitamins (19.5\%), ginseng products $(9.0 \%)$, mineral supplements (5.9\%), herbal medicines $(4.5 \%)$, and others $(2.7 \%)$ as multiple-choice. Significant difference of choice for functional supplements was observed between male and female $(\mathrm{p}<0.01)$, as well as middle- and high-school students $(\mathrm{p}<0.01)$ respectively.

Table 1: Prevalence of functional supplement use and types in Korean adolescents

\begin{tabular}{|c|c|c|c|c|c|}
\hline \multirow{2}{*}{$\begin{array}{c}\text { Subjects } \\
\text { Sex }\end{array}$} & \multicolumn{2}{|c|}{$\begin{array}{l}\text { Middle school students } \\
(2,254)\end{array}$} & \multicolumn{2}{|c|}{$\begin{array}{l}\text { High school students } \\
(2,455)\end{array}$} & \multirow{2}{*}{$\begin{array}{c}\begin{array}{c}\text { Total } \\
(\mathbf{4 , 7 0 9 )}\end{array} \\
\text { Statistical analysis }\end{array}$} \\
\hline & Male & Female & Male & Female & \\
\hline Number of subjects & 650 & 1,604 & 1,808 & 647 & $\begin{array}{l}\text { M: } 2,458 \\
\text { F: } 2,251\end{array}$ \\
\hline Range of age (year) & $13 \sim 16$ & $13 \sim 16$ & $17 \sim 19$ & $17 \sim 19$ & $13 \sim 19$ \\
\hline Mean height & $164.9 \pm 13.1$ & $158.6 \pm 8.8$ & $173.8 \pm 9.2$ & $160.8 \pm 12.1$ & $\begin{array}{l}\text { M: } 171.5 \pm 11.1 \\
F: 159.3 \pm 10.0\end{array}$ \\
\hline Mean body weight & $54.5 .4 \pm 11.5$ & $48.2 \pm 12.8$ & $66.2 \pm 12.5$ & $51.9 \pm 6.9$ & $\begin{array}{l}M: 63.3 \pm 13.2 \\
F: 49.3 \pm 11.5\end{array}$ \\
\hline
\end{tabular}

\begin{tabular}{|c|c|c|c|c|c|}
\hline \multicolumn{6}{|c|}{ User ratio of functional supplements } \\
\hline Number of users & 192 & 495 & 734 & 264 & $\begin{array}{l}M: H=687: 998 \\
M: F=926: 759\end{array}$ \\
\hline Ratio of users & $29.5 \%$ & $30.9 \%$ & $40.6 \%$ & $40.8 \%$ & $\begin{array}{c}\text { Total: } 35.8 \% \\
*_{\mathrm{M}}: \mathrm{H}=30.5 \%: 40.7 \% \\
*_{\mathrm{M}}: \mathrm{F}=37.7 \%: 33.7 \%\end{array}$ \\
\hline \multicolumn{6}{|c|}{ *Types of functional supplements (Frequency and \%, multiple choice) } \\
\hline Vitamins & $86(13.2 \%)$ & $293(18.3 \%)$ & $378(20.9 \%)$ & $157(24.3 \%)$ & $\begin{array}{c}\text { Total: } 19.5 \% \\
M: H=16.8 \%: 21.8 \% \\
M: F=18.9 \%: 20.0 \%\end{array}$ \\
\hline Ginseng products & $48(7.4 \%)$ & $97(6.1 \%)$ & $218(12.1 \%)$ & $60(9.3 \%)$ & $\begin{array}{c}\text { Total: } 9.0 \% \\
M: H=6.4 \%: 11.3 \% \\
M: F=10.8 \%: 7.0 \%\end{array}$ \\
\hline Minerals & $33(5.1 \%)$ & $82(5.1 \%)$ & $121(6.7 \%)$ & $43(6.7 \%)$ & $\begin{array}{c}\text { Total: } 5.9 \% \\
M: H=5.1 \%: 6.7 \% \\
M: F=6.3 \%: 5.6 \%\end{array}$ \\
\hline Herbal medicines & $29(4.5 \%)$ & $52(3.2 \%)$ & $97(5.4 \%)$ & $35(5.4 \%)$ & $\begin{array}{c}\text { Total: } 4.5 \% \\
M: H=3.6 \%: 5.4 \% \\
M: F=5.1 \%: 3.9 \%\end{array}$ \\
\hline Others & $18(2.8 \%)$ & $47(2.9 \%)$ & $39(2.2 \%)$ & $24(3.7 \%)$ & $\begin{array}{c}\text { Total: } 2.7 \% \\
M: H=2.9 \%: 2.6 \% \\
M: F=2.3 \%: 3.2 \%\end{array}$ \\
\hline
\end{tabular}

The comparisons of the frequency between middle- and high-school students (M : H), and male and female (M : F) as well as choice of functional supplements using Chi-square test.* indicates statistical significance as $\mathrm{p}<0.001$. 


\section{http://dx.doi.org/10.4314/ajtcam.v11i1.4}

\section{Discussion}

Korean adolescents are known to be under physical and psychological stress due to stiff academic competition and long study hours (Shin et al, 2009). In a recent report, $46.6 \%$ of Korean high-school students complained of at least one physical indicator of stress whereas $31.0 \%$ were under severe emotional stress (Seo et al, 2010). The students frequently used functional supplements or herbal medicines to combat fatigue, which was the primary reason for the increased consumption in high-school compared to middle-school students.

No data currently exist comparing the prevalence of functional supplement consumption in Korean adolescents with those of other countries. It has been reported that $20 \%$ of the Dutch population (1,183 subjects, aged 19-91 years) consumes multivitamins or mineral supplements daily, and that $3-9 \%$ of the population uses other products (de Jong et al, 2003). ${ }^{5}$ The population frequency of functional supplement consumers and the products being consumed differ depending on age, ethnicity, and economic status. In Korea, ginseng and herbal medicines have been used for thousands of years; thus, Korean adolescents select ginseng products or herbal medicines more often than their Western counterparts.

In summary, this study is the first to demonstrate the features of functional supplement consumption among Korean adolescents, and it provides reference data for future studies on functional foods or supplements.

\section{Acknowledgements}

This research was supported by the "Study of aging-control by energy metabolism based on oriental medicine (K13101)" funded by "KM-Based Herbal Drug Research Group" of Korea Institute of Oriental Medicine. The English in this document has been checked by at least two professional editors, both native speakers of English. For a certificate, please see: $\underline{\text { http://www.textcheck.com/certificate/38a7sq }}$

\section{References}

1. de Jong, N., Ocké, M.C., Branderhorst H.A. and Friele, R. (2003). Demographic and lifestyle characteristics of functional food consumers and dietary supplement users. Br J Nutr., 89:273-381.

2. Pascal, G. (2009). Safety impact--the risk/benefits of functional foods. Eur J Nutr., 48:S33-39.

3. Seo, K.S., Ahn, Y.C. and Son, C.G. (2010). Survey for general traits of health-associated factors of high school students in Daegeon City. J. Korean Oriental Med., 31:171-177.

4. Shin, Y.H. and Ahn, Y.H. (2009). A mentoring program for stress management among Korean adolescents. J. Korean Acad. Community Health Nurs., 20:259-268.

5. Vergari, F., Tibuzzi, A. and Basile. G. (2010). An overview of the functional food market: from marketing issues and commercial players to future demand from life in space. Adv. Exp. Med. Bio., 698:308-321. 